\title{
Design and Reliability of a High Voltage, High Current Solid State Switch for Magnetic Forming Applications
}

\author{
A. Welleman, R. Leutwyler and S. Gekenidis \\ ABB Switzerland Ltd, Semiconductors, Fabrikstrasse 3, CH-5600 \\ Lenzburg, Switzerland
}

\begin{abstract}
The presentation will give an overview of the design, construction, test and reliability of a solid state switch assembly used for magnetic forming applications. In 2005 a prototype of a reverse conducting semiconductor switch for $210 \mathrm{kA}$ at $100 \mu$ s damped sine wave discharge and $21 \mathrm{kV}$ dc was designed to be used in an experimental system at the Fraunhofer Institute at Chemnitz (Germany). The aim was to show the industry that semiconductors can be used for this type of applications. Precautions in the design stage have to be taken to reach high operational lifetime. The presented prototype switch was designed for an expected lifetime of 20000 shots under nominal and 1000 shots under short circuit conditions of $420 \mathrm{kA}$. After successful commissioning, further tests were done on separate semiconductor devices to verify under which conditions the lifetime could be increased to several million shots for the given application. For this verification, ABB has done extended device tests over more than one million shots and the wafers were analysed. The results of the reliability test are part of this presentation. It will be concluded that proper designed solid state switches are economically feasible, free from maintenance and despite higher initial cost are more reliable and superior to any other technology existing today.
\end{abstract}

PACS numbers: 84.30.Jc, 84.32.Dd

\section{Device technology}

The semiconductor devices selected for this application are based on silicon wafers of the integrated gate commutated thyristor (IGCT) or gate turn-off (GTO) technology and optimized as capacitor discharge devices. As there is no turn-off requirement, the devices are fully optimized for fast switch-on with high $\mathrm{d} i / \mathrm{d} t$ capability of up to $25 \mathrm{kA} / \mu \mathrm{s}$. Because some applications have a damped sine wave it is possible to integrate a diode monolithic on the same silicon wafer.

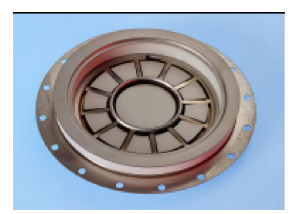

Fig. 1. Housing.

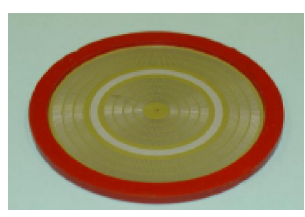

Fig. 2. Wafer.

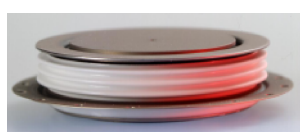

Fig. 3. Device.

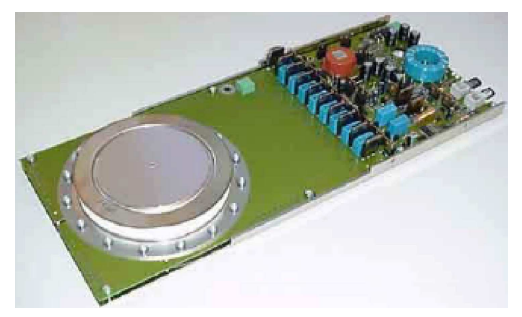

Fig. 4. Device with driver unit.

In Fig. 1 the low inductive housing of the semiconductor device is shown. Figure 2 shows the $91 \mathrm{~mm}$ silicon wafer, Fig. 3 the complete semiconductor device and Fig. 4 the complete switching device including integrated driver unit. The switching capability of the asymmetric blocking $\left(V_{\mathrm{drm}}=4500 \mathrm{~V}, V_{\mathrm{rrm}}=17 \mathrm{~V}\right)$ device is up to $150 \mathrm{kA}$ at $100 \mu \mathrm{s}$ and for the reverse conducting version with integrated diode $\left(V_{\mathrm{drm}}=4500 \mathrm{~V} / V_{\mathrm{rrm}}=0 \mathrm{~V}\right)$ up to $100 \mathrm{kA}$ at $100 \mu \mathrm{s}$. Triggering is done by a very strong gate-pulse in the range of approximately. $600 \mathrm{~A}$ and $\mathrm{d} i / \mathrm{d} t$ of $1 \mathrm{kA} / \mu \mathrm{s}$. The driver units are designed 
to be used in series connection and are energized by a separate current source power supply using $25 \mathrm{kHz} / 4 \mathrm{~A}$. A high voltage cable transfers the energy to the input transformer to energize the gate-unit. An optical signal will trigger the gate unit and than trigger the device itself.

\section{Reverse conducting discharge switch $210 \mathrm{kA} / 21 \mathrm{kVdc} / 100 \mu \mathrm{s}$}

In 2005 a prototype switch assembly for magnetic forming was designed and produced using reverse conducting devices ABB p/n 5SPR 26L4506. Table I shows the basic specification which had to be fulfilled.

TABLE I

Specification for reverse conducting $210 \mathrm{kA} / 21 \mathrm{kV}$ switch assembly.

\begin{tabular}{l|c|c}
\hline \hline Parameter & Normal & Short circuit \\
\hline Max. charge voltage & $21 \mathrm{kVdc}$ & $21 \mathrm{kVdc}$ \\
Peak pulse current forward & $210 \mathrm{kA}$ & $420 \mathrm{kA}$ \\
Peak pulse current reverse & $90 \mathrm{kA}$ & $150 \mathrm{kA}$ \\
Current rise rate $(\mathrm{d} i / \mathrm{d} t)$ & $3 \mathrm{kA} / \mu \mathrm{s}$ & $9 \mathrm{kA} / \mu \mathrm{s}$ \\
Pulse duration & $100 \mu \mathrm{s}$ & $50 \mu \mathrm{s}$ \\
Pulse form & damped sine & damped sine \\
Pulse repetition rate & 1 shot $/$ min & 1 shot $/ 10 \mathrm{~min}$ \\
Lifetime & 20000 shots & 1000 shots
\end{tabular}

To withstand the $21 \mathrm{kV}$ dc charge voltage, 8 devices $5 \mathrm{SPR} 26 \mathrm{~L} 4506\left(V_{\mathrm{drm}}=4500 \mathrm{~V} / V_{\mathrm{dc}}=2800 \mathrm{~V}\right)$ have to be used in series connection. To fulfil the requirement of $210 \mathrm{kA}$ nominal current and $420 \mathrm{kA}$ short circuit condition, three devices in parallel are needed to reach the 20000 shot lifetime. This means for the complete switch $N_{s}=8$ and $N_{p}=3$ total 24 devices are used (Fig. 5).

Because reverse conducting devices are used and no switch-off capability is required, no snubber circuit is needed, only voltage sharing resistors over every device. Three independent stacks are used in parallel to avoid hard parallel connection of 3 devices. Every stack can handle $70 \mathrm{kA}$ nominal/140 kA short circuit. The driver units are powered by one closed loop current source power supply per stack and each device is optically triggered from a light distribution box. Figure 6 shows one of three stack assemblies of the switch, cooled by air convection.

Compared to Ignitrons and Spark Gaps, solid state switches have very good lifetimes, but have not infinite life. For a semiconductor device the design and the production processes are most important. Quality- and process management in the wafer fabrication are of vital importance. The lifetime of a semiconductor is in the application mostly limited by mechanical stress or cosmic ray. Mechanical stress is caused by temperature steps in the silicon due to current pulses. The temperature of the silicon can increase more than $100^{\circ} \mathrm{C}$ within some $\mu \mathrm{s}$ and the larger these temperature steps are the shorter lifetime is expected. Therefore it is important to avoid large temperature steps if long life and high reliability is

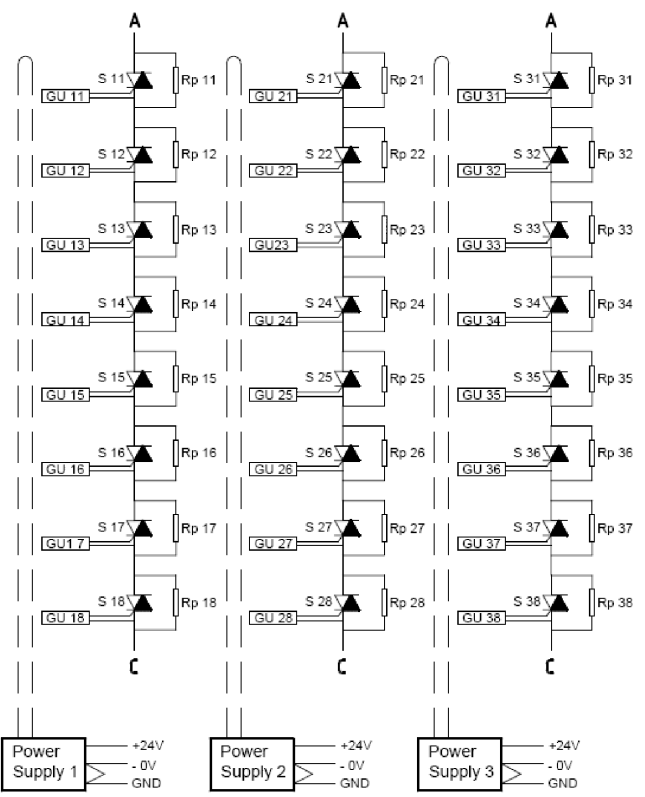

Fig. 5. Circuit diagram of $21 \mathrm{kV}$ switch.

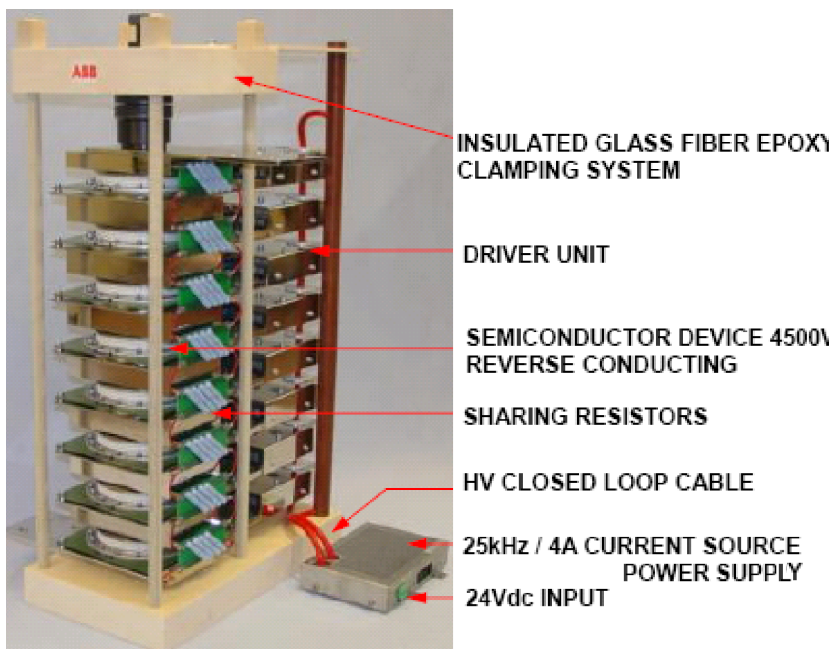

Fig. 6. Stack assembly with 8 devices in series connection. The $21 \mathrm{kV} / 210 \mathrm{kA}$ Switch consists of 3 stacks in parallel. Each one for $70 \mathrm{kA}$ current rating.

required. To accomplish this, high reliability systems will have more or larger size devices which means often higher costs. Important is also the influence of cosmic ray on the silicon wafer. To reach an acceptable FIT rate (1 FIT is 1 failure in $10^{-9} \mathrm{~h}$ ) per device of $\leq 100 \%$ it has to be made sure that the DC voltage on the device is maximally $65 \%$ of the device blocking capability. This means that a device with $V_{\mathrm{drm}}=4500 \mathrm{~V}$ should not be charged with higher DC voltage as $2900 \mathrm{Vdc}$. In case of higher DC voltage the device will have a reduced lifetime. The experimental switch was designed for 20000 shots with a repetition rate of 1 shot per minute but a production line in the industry will need $\geq 2$ Mio shots with a repetition 
rate of one shot every 15 seconds. Therefore ABB has made calculations and several tests to verify the difference.

\section{Test conditions}

To verify the reliability of the switch some device tests were made under application conditions. Table II shows an overview of the different tests and conditions. For every test two devices in series connection were used with $V_{\mathrm{dc}}=1800 \mathrm{~V} /$ device. The test were done with a pulse repetition rate of 1 shot per $6 \mathrm{~s}$ which is $2.5 \times$ more as specified in the application. Still the devices did not need any additional cooling.

TABLE II

Overview of tested devices and shot.

\begin{tabular}{c|c|c|c|c|c|c|c}
\hline \hline $\begin{array}{c}\text { Test } \\
\text { No. }\end{array}$ & Devices & Date & Vdc & $I$-pulse & $t$-pulse & $\begin{array}{c}\text { Rep. } \\
\text { rate }\end{array}$ & Shots \\
\hline 1 & $\begin{array}{c}5 \mathrm{SPR} \\
26 \mathrm{~L} 4506\end{array}$ & 27.04 & 2800 & $70 \mathrm{kA}$ & $100 \mu \mathrm{s}$ & $6 \mathrm{~s}$ & 20260 \\
\hline 2 & $\begin{array}{c}5 \mathrm{SPR} \\
26 \mathrm{~L} 4506\end{array}$ & 20.06 & 2800 & $31 \mathrm{kA}$ & $100 \mu \mathrm{s}$ & $6 \mathrm{~s}$ & 252600 \\
\hline 3 & $\begin{array}{c}5 \mathrm{SPR} \\
26 \mathrm{~L} 4506\end{array}$ & 26.08 & 2800 & $31 \mathrm{kA}$ & $100 \mu \mathrm{s}$ & $6 \mathrm{~s}$ & 1040000
\end{tabular}

Test No. 1. After the $70 \mathrm{kA}$ test the two devices were still functioning but leakage current was increasing at $2.8 \mathrm{kVdc}$ and higher. Changes were found at the cathode contact finger and some molten craters on the aluminium metallisation layer at the anode side of the wafer. These changes are indicating that the end of life for the wafer is very near.

Test No. 2. The $31 \mathrm{kA}$ test with 4 devices was interrupted after 252600 shots to verify the changes under these conditions on two out of four devices. All devices were still functioning. It was found that there was no increase of leakage current at $2.8 \mathrm{kVdc}$ and there was almost no change to the aluminium layer on the anode side of the wafer. The little change was an indication that there was no problem with life-time. The test was continued with the remaining two devices.

Test No. 3. The $31 \mathrm{kA}$ test was stopped after 1040000 shots and the two devices analysed. Both devices were still functioning. The analysis has shown that there was no increase of leakage current at $2.8 \mathrm{kVdc}$ but some small molten spots in the aluminium contact layer of the anode. By analysing the spots it could be confirmed that under these conditions about $50 \%$ of the device lifetime was consumed.

\section{Conclusion}

It can be concluded that the devices used for the experimental $100 \mathrm{~kJ} / 21 \mathrm{kV} / 210 \mathrm{kA}$ discharge switch are a reliable solution. For industrial use however the lifetime has to be increased. The test results with the $200 \mathrm{kA}$ switch using $N_{p}=3$ devices (70 kA per device) compared to a $210 \mathrm{kA}$ switch using $N_{p}=6$ (31 kA per device) shows that by almost doubling the silicon area, an increase in lifetime by a factor of 50 can be reached. This also means that a $50 \times$ higher reliability will double the cost of the semiconductor switch assembly. Despite the higher initial costs, the solid state design offers a much higher reliability, longer life-time and lower operation costs.

Due to the limited space in this presentation format the pictures of the test results and analysis could not be presented but the full paper is available at $\mathrm{ABB}$ on request. 